\title{
Redes de poder y sociabilidad en la élite política chilena. Los parlamentarios 1990-2005*
}

\author{
Vicente Espinoza**
}

\begin{abstract}
Resumen: Desde el retorno de la democracia en Chile, la alianza política que alcanzó el gobierno consolidó sus posiciones de poder e influencia sin conocer por 20 años alternancia o grandes cambios en sus formas de gestión. Aunque el control del gobierno cambió a una coalición diferente en 2010, la agrupación previa continúa existiendo y posee una significativa representación en el parlamento. ¿Qué expresa tal estabilidad? El argumento principal en este artículo es que un origen social similar de los parlamentarios unido a una interacción social frecuente reduce el dramatismo de las diferencias ideológicas haciendo así más probable las transformaciones políticas o el cambio del grupo en el poder. El análisis considera datos sociodemográficos de los parlamentarios, así como datos de redes sociales de una muestra 37 parlamentarios en ejercicio y 20 que lo hicieron entre 1990 y 2004. El origen social de los parlamentarios corresponde en forma creciente a un medio social similar, caracterizado por escolarización en establecimientos privados y universidades, alcanzando un status socioeconómico relativamente alto. El mapa de sus redes sociales muestra que el clivaje ideológico entre dictadura y democracia alcanzó también las relaciones sociales, estableciendo gran distancia social entre los políticos que hoy dominan la escena. El mapa permite apreciar también un nuevo campo político socialmente más diverso, en el cual tienen relevancia políticos más jóvenes, líderes regionales y la universidad como espacio de encuentro entre políticos e intelectuales.
\end{abstract}

Palabras clave: redes de poder, sociabilidad, élite política, parlamentarios.

\section{Social basis of power dynamics in the Chilean political elite. Personal networks of parliamentarians, during 1990-2005}

\begin{abstract}
Since democracy returned to Chile in 1990, the political block that gained the government that time ruled the country during 20 years. Although government's control changed to a different coalition in 2010, the previous block continues to exist and retains control in parliament. How could one understand that stability? This article pursues a line of inquiry based on the hypothesis that a similar social origin of parliamentarians as well as frequent social interaction would soften ideological differences making more likely political transformations or even the change of the group in power. The analysis considers socio-demographic data and network data for a sample of 37 current and 20 former parliamentarians. The
\end{abstract}

\footnotetext{
* Los datos de la investigación fueron generados en el marco del proyecto Fondecyt $\mathrm{N}^{\circ} 1070199$

** Universidad de Santiago, Santiago, Chile. Email: vicente.espinoza@usach.cl
} 
results show that parliamentarians are increasingly recruited from a homogeneous social circle, characterized by high socioeconomic status, attending to private schools and pursuing university careers. The map of their social relations focused on active strong social ties, shows that the ideological division between dictatorship and democracy penetrated deep into the social structure, establishing a large social distance between politicians. The social map also shows an emerging socially diverse political arena composed of younger politicians and regional leaders, who find in universities their preferred milieu.

Key words: power networks, sociability, political elite, parliamentarians.

\section{Redes de poder e sociabilidade nas elites políticas chilenas. Os parlamentares 1990-2005}

Resumo: Desde o retorno da democracia no Chile, a aliança política que alcançou o governo consolidou a sua posição de poder e influência sem conhecer, por 20 anos, alternância ou grandes mudanças em suas formas de gestão. Embora o controle do governo tenha mudado para uma coligação diferente em 2010, a agrupação prévia continua existindo e possui uma representação significativa no parlamento. O que expressa esta estabilidade? O argumento principal deste artigo é que uma origem social similar dos parlamentares unidos a uma interação social freqüente reduz o dramatismo das diferenças ideológicas, fazendo assim mais provável as transformações políticas ou a mudança do grupo no poder. A análise considera dados sociodemográficos dos parlamentares, assim como dados de redes sociais de uma amostra de 37 parlamentares em exercício e 20 que o fizeram entre 1990 e 2004 . A origem social dos parlamentares cada vez mais corresponde a um ambiente social semelhante, caracterizado pela escolarização em instituições privadas e em universidades, atingindo um status socioeconômico relativamente alto. O mapa das suas redes sociais revela que a clivagem ideológica entre ditadura e democracia atingiu também as relações sociais, estabelecendo uma grande distância social entre os políticos que hoje dominam a cena. O mapa permite apreciar, também, um novo campo político socialmente mais diverso, no qual tem relevância políticos mais jovens, líderes regionais e a universidade como espaço de encontro entre políticos e intelectuais.

Palavras-chave: Redes de poder, sociabilidade, elite política, parlamentares.

Recibido: 04.09.2009

Aceptado: 26.11.2009

Que en un régimen democrático una minoría de representantes o altos funcionarios tome decisiones que afectan al conjunto de la población, naturalmente levanta preguntas acerca de los fundamentos de tales decisiones en tanto búsqueda del bien público. Por cierto el poder de representantes y funcionarios se ejerce en un marco institucional que lo regula, pero no por ello dejan de surgir preguntas apremiantes: ¿Quién los selecciona? ¿De dónde viene su poder? ¿Se representan a sí mismos o están vinculados con otros grupos sociales? Las respuestas a estas preguntas son las que busca entregar un estudio de élites, verificando empíricamente las razones asociadas con la preeminencia de una minoría, así como sus mecanismos de selección. 
Hay abundante evidencia de que aún en democracia el gobierno lo ejerce una minoría -que Pareto ([1916] 1935) identifica con una élite y que Mosca ([1896] 1984) denomina la clase política- lo cual constituye prácticamente un axioma del análisis político (Michels [1911] 1983, Putnam 1976). No es posible saltar, sin embargo, desde la identificación de una minoría con poder a la conclusión de que ésta posee un poder absoluto. El problema de investigación consiste en establecer la distancia entre la presencia de una minoría en posiciones de autoridad clave y el grado de control que ejercen sobre la mayoría.

En América Latina, el uso más reciente del concepto de élite se asocia con la caracterización de la democracia en operación desde 1990, dentro de la cual a este grupo se le asigna un rol decisivo. En la transición desde la dictadura a la democracia, los acuerdos explícitos de la élite sobre instituciones políticas constituirían una condición necesaria para dar sustentabilidad al proceso (Cavarozzi 1992, O’Donnell el al. 1986). En un sistema político presidencialista como el chileno, el establecimiento de consensos al interior de la élite política aparece como condición para evitar el bloqueo mutuo entre el ejecutivo y el legislativo (Nolte 2003). Este tipo de formulaciones se pueden asimilar con un modelo general de "democracia consociativa” en la cual las élites poseen un rol central en la gestión de las instituciones democráticas y la gestión del conflicto político a través del establecimiento de acuerdos (Highley et al 1991, Ruiz 1993).

Si bien una élite unificada puede asegurar una democracia estable, su predominio dice directa relación con el ejercicio del poder y la calidad de la representación, porque el peso que adquiera una minoría entra inevitablemente en tensión con los principios de un régimen democrático. En Chile, esta preocupación se vincula estrechamente con el intento por caracterizar los grupos que en las últimas dos décadas ha logrado consolidarse en posiciones de poder e influencia. Si bien la Concertación de Partidos por la Democracia perdió el control del ejecutivo en 2010, lo hizo por estrecho margen, frente a la Coalición por el Cambio, que por 20 años fue la oposición de la coalición gobernante. Más aún, a pesar de su derrota presidencial la Concertación continúa existiendo y posee dos diputados menos y dos senadores más que la Coalición ¿Cómo entender la estabilidad de los grupos en el poder? ¿ ¿Se trata de unos privilegiados que mantienen su posición gracias a su capacidad para excluir al resto? ¿O su estabilidad dice relación con la capacidad para incorporar en su seno a los mejores, renovando su composición?

La constitución de la élite política en tanto que objeto de investigación requiere de un trabajo sistemático sobre el conjunto de relaciones establecido entre los diferentes actores del campo político, vale decir, las redes sociales que les vinculan. Este trabajo no se ha realizado aún en Chile, pues la mayor parte de los estudios sobre élites políticas las asimilan con posiciones de autoridad formal y se concentran en su proximidad ideológica. En realidad, ganar una posición en la élite política constituye el punto culminante de una trayectoria individual al interior de una red social -un 
proceso de movilidad vertical- en el cual el aspirante al poder acumula experiencia, clientelas, mentores y otros recursos, los cuales gestiona relacionalmente.

Este artículo presenta los resultados de una investigación desarrollada en Chile en el marco del Proyecto Fondecyt $\mathrm{N}^{\circ} 1070199$, sobre una muestra representativa de diputados electos entre 1989 y 2005. El proyecto elaboró un mapa social de la élite política, tomando en consideración sus lazos internos y las relaciones con personas de otros círculos sociales y que no ocupan necesariamente posiciones formales de poder, pero que resultan clave para asegurar la posición de los representantes formales. La información analizada comprende también datos provenientes de Reseñas Biográficas de Parlamentarios que publica la Biblioteca del Congreso Nacional e información de prensa. La información primaria proviene de entrevistas de redes realizadas a 52 diputados y 6 senadores que han ejercido entre 1990 y 2005, las cuales fueron realizadas en dos olas durante 2007 y $2008^{1}$.

\section{Por qué y hasta cierto punto para qué estudiar las élites}

Desde su introducción a comienzos del siglo XX, el concepto de élite ocupó un lugar central en el estudio de los sistemas políticos y de la estratificación social, dada la prominencia que alcanzaban posiciones exclusivas (Scott 2008). A mediados de los años 1950 con la publicación de La Élite del Poder se inició un debate destinado a precisar el status de este concepto en la teoría social (Mills [1956] 1987). Desde la perspectiva de este autor, la élite del poder consistía en un entramado de relaciones sociales entre las autoridades de los campos económico, político y militar, quienes alternaban posiciones en estos tres ámbitos. Su posición fue radicalizada por los marxistas, quienes intentaban mostrar que tal élite no era otra cosa que una clase dominante afincada en última instancia en su poder económico (Domhof 1967, Miliband 1974, Giddens 1974). De otro lado, los pluralistas criticaron la dificultad para identificar empíricamente una élite del poder que expresara prevalencia de los intereses de una minoría en decisiones políticas clave (Dahl 1958). Igualmente pusieron en duda la inmutabilidad de los grupos dominantes a los que hacía referencia, así como los supuestos de unidad interna, planteando que el proceso de toma de decisiones involucra competencia entre múltiples grupos de interés preocupados de asuntos específicos (Bottomore 1964).

\footnotetext{
${ }^{1}$ La dedicación y rigurosidad de la socióloga Cristina San Martín en la implementación del trabajo de campo constituyen un aporte clave para contar con la información que se analiza en el proyecto. El equipo de trabajo contó también con la participación del coinvestigador Dr. Robert Funk, la Doctora Cristina Moyano y el Tesista Sociólogo Cristián Jamett, quienes participaron en reuniones de discusión, aportaron contactos y colaboraron con algunas entrevistas. Finalmente, Violeta Rabi armó la base de datos a partir de las transcripciones de la segunda ola de entrevistas, lo cual permitió abordar el análisis que presenta este artículo. Como corresponde, las insuficiencias del artículo son de mi exclusiva responsabilidad.
} 
En el marco de este debate, los estudiosos de las redes sociales sostuvieron que las configuraciones centralizadas o descentralizadas que intervenían en el proceso de toma de decisiones podían ser analizadas como casos dentro del marco unificado que ofrecía el enfoque de redes sociales (Alba \& Moore 1983, Kadushin 1968, Highley et al. 1991). De esta forma se abrió un campo de estudios destinado a identificar con precisión la composición y estructura de la élite. Tales estudios abrieron la pregunta acerca de la unidad interna de la élite, utilizando un enfoque que permitía esclarecer su cohesión o solidaridad.

Desde un ángulo más propiamente sociológico, estos estudiosos plantearon que la comunicación y vinculaciones sociales entre miembros de la élite contribuirían a reducir el conflicto incrementando la solidaridad interna (Moore 1979). La cohesión aparece cuando la movilidad social, encuentros sociales, matrimonios cruzados, educación establecen vínculos entre sus miembros (Scott 2008). La existencia de estos vínculos tiene consecuencias para la conformación y características que posea la élite en cuanto a su conciencia de tal y su capacidad de acción conjunta. La homogeneidad o densidad interna de un grupo de élite, en este caso la élite política es el tema que se aborda en este artículo a partir del análisis de la estructura de sus relaciones sociales.

El conjunto de contactos personales puede entenderse como un "capital social” en la medida que la posición social reporta beneficios individuales (Burt 1992, Espinoza 1999, Portes 1998). La perspectiva ha sido desarrollada por quienes por quienes buscan la base relacional de las desigualdades en el acceso a recursos (Bourdieu \& Wacquant 1992, Burt 1992, Lin 2001). Las vinculaciones entre diversas redes personales establecen una estructura social en la cual la posición individual condiciona las posibilidades de acceso a recursos (Burt 1992, Lin 2001). Incluso, la dotación de capital social u otros capitales que posee un individuo, le permite definir estrategias de posicionamiento o conversión dentro de su campo (Bourdieu \& Wacquant 1992). La generación de valor para un centro -que puede ser individual o colectivo- a partir de sus redes permite distinguir al capital social del estudio de las relaciones sociales en general. Retomando la clásica expresión de Granovetter (1985), las relaciones económicas aparecen engarzadas en las relaciones sociales.

Las redes sociales de tipo individual pueden ofrecen indicaciones fuertes respecto de las formas de integración social de la élite tanto internamente como verticalmente. El tamaño de las redes se asocia habitualmente con la diversidad interna y la fuerza de los vínculos; redes más pequeñas indican mayor homogeneidad y vinculaciones más estrechas. La composición de las redes personales permite calificar la diversidad identificando los círculos sociales a los cuales pertenecen los contactos y el tipo de recursos asociados con éstos. La homogeneidad interna indicaría una estructura de alta segmentación, probablemente con rasgos estamentales, mientras que la heterogeneidad muestra estructuras sociales más permeables, con acceso a diversidad de estilos, prácti- 
cas, recursos o información; que enriquecen la experiencia individual.

Un aspecto diferente de las redes personales se refiere a la redundancia de los contactos, pues las redes con menor redundancia permiten explotar mejor el acceso a círculos sociales diversos, a la vez que reducen la dependencia de un contacto estratégico (Burt 2005). En el estudio de redes personales se ha acuñado el concepto de multiplicidad para referirse a un lazo personal que canaliza diversos recursos o que mantiene en diversos contextos, o que comprende diversos roles. La mayor redundancia o la presencia de vínculos múltiples indica, por lo tanto, una baja especialización de la red (Wellman \& Wortley 1991, Wellman 2000).

El análisis combinado de las redes personales permite establecer la estructura interna de la élite en la medida que existen contactos compartidos entre los entrevistados. La propiedad básica de la red en este caso se refiere a la capacidad de comunicación entre sus integrantes. Dependiendo de la pauta de relaciones, la comunicación puede ser imposible cuando la red está desconectada, dificultosa si hay poca disponibilidad de mediación, engorrosa si requiere de muchos mediadores o directa si sus integrantes están vinculados a corta distancia. Muy cercano a lo anterior se encuentra la identificación de grupos internos, círculos sociales o facciones basadas en la comunicación frecuente. Las cualidades de la comunicación interna de una red inciden directamente en la capacidad de coordinación y acción conjunta.

\section{Unidad e integración de la élite política}

Las relaciones al interior de la élite política están incrustadas en redes de relaciones sociales que suponen interacción personal. Como lo señala la literatura especializada, una socialización común de los miembros de la élite política ${ }^{2}$-en familias, colegios, universidades, comunidades religiosas o clubes- ofrece una base de confianza para el logro y operación de acuerdos propiamente políticos, porque establece un campo normativo común y permite el control social de los acuerdos (Coenen-Huther 2004, Rabkin 1996). Desde este punto de vista, la élite política no está necesariamente determinada por sus relaciones sociales, sino que éstas facilitan su integración horizontal y el desarrollo de las funciones propiamente políticas. La posibilidad de interacción social “cara a cara” condiciona la emergencia de élites cohesionadas, en la medida que la común

\footnotetext{
${ }^{2}$ El término “socialización” comprende una dimensión de internalización de valores o pertenencia a una cultura, y otra de "sociabilidad" vale decir la pertenencia o participación en un campo de actores mutuamente referidos. En el artículo la perspectiva de análisis pone su énfasis en la segunda dimensión. Este uso más restringido no corresponde totalmente con la conceptualización de los estudios clásicos de socialización política que buscaron establecer asociaciones entre orientaciones ideológicas y origen social o socialización primaria (Hyman 1959, Putnam 1976).
} 
concurrencia a determinados espacios sociales, las dinámicas de producción simbólica y formación de representaciones de la realidad resultan congruentes en sus contenidos. Operativamente ello se expresa en una serie de co-membresías (grupos religiosos, centros de estudio, partidos) o participación conjunta en eventos (exilio, campañas).

La capacidad de la élite para profundizar su cohesión interna se apoyaría en una comunidad política y cultural que antecede su participación como agente político. Al respecto, Sawicki (1997), estudiando los militantes socialistas franceses reconoce las limitaciones del tratamiento de la militancia en partidos políticos como un agregado de preferencias ideológicas individuales. Su estudio destaca el papel que juega la socialización política de los militantes, de forma que ella luego se expresa en los liderazgos regionales. Por ello propone utilizar las "redes" como referente estructural, las cuales entiende como espacios en los cuales se agregan, se articulan y, en definitiva se hacen orgánicos los colectivos que operan a escala local. La matriz de adhesión así identificada corresponde a grupos formados en un proceso de socialización política que opera al interior de las categorías estructurales, en familias, clubes, círculos de amistad, entre otros. En otras palabras, los criterios de diferenciación al interior de grandes bloques políticos se expresan como matrices de adhesión, cuya referencia estructural remite en último término a redes de socialización/sociabilidad política.

En una línea de argumentación similar, aplicada al caso de los partidos políticos de centro en Chile, Larissa Adler y Ana Melnick (1998) destacan la importancia de las redes horizontales dentro de esos conglomerados. La estructura de redes informales de la élite chilena determinaría la institucionalización de ciertas estructuras formales como los partidos políticos. Para las autoras, los eventos de fragmentación o faccionalismo moderado que aparecen como fenómenos predominantes en los partidos analizados, tienen como función limitar los liderazgos y reducir el peso de las estructuras jerárquicas (Adler y Melnick, 1998:25).

Otros elementos relativos al peso de la socialización pueden encontrarse en el análisis histórico de los militantes políticos chilenos. Gazmuri (2001) ha identificado un conjunto de focos de interacción en la Universidad Católica que posibilitaron el origen y la evolución de movimientos "político-intelectuales" de jóvenes con alta incidencia en el desarrollo del país, como la ANEC, la "Liga Social” y principalmente, la Falange Nacional. Posteriormente, al llegar la década de los sesenta, el mismo espacio institucional verá nacer otros tres grupos fundamentales, como el MAPU, los Chicago Boys y el Gremialismo. La "vocación de servicio público" de la nueva generación de políticos derechistas, especialmente los militantes de la UDI encuentra en la Universidad Católica su espacio privilegiado de socialización política, la cual continuarían en los servicios públicos. Al analizar las biografías de los dirigentes estudiantiles gremialistas, Huneeus (2002) pone en evidencia que la mayor parte de ellos tuvo una trayectoria política semejante: primero en los servicios públicos en los cuales el 
gremialismo logró asentarse, luego como alcaldes designados de la dictadura y, finalmente como parlamentarios electos.

Un grupo de estudios recientes acerca de la élite social y política chilena destaca la homogeneidad social y cultural del grupo dirigente como uno de los factores de mayor peso en su constitución. Un estudio de tipo longitudinal, basado en datos de una encuesta del año 2000 apunta a la homogeneidad social y cultural en la élite, la cual aparece más abierta y heterogénea que en los años $1950^{3}$. Joignant y Navia (2003) al revisar los factores asociados con el crecimiento electoral de la UDI entre 1990 y 2000 destacan precisamente tal permeabilidad. Cordero (2007) realiza una comparación entre las características socio-demográficas de los diputados chilenos en dos etapas: desde 1961 a 1973 y desde 1990 a 2010. Las diferencias encontradas por este último autor apuntan hacia una mayor homogeneidad de origen social para el segundo período.

Otro grupo de estudios busca establecer líneas de diferenciación al interior de este grupo. Hardy (2005) pone su foco en las mujeres que participan en la élite política a las cuales busca caracterizar en términos de su origen social, cultura y trayectorias, para establecer sus posibilidades de renovar la composición de la élite. El estudio del PNUD (2005) sobre el poder en la sociedad chilena aborda diversas dimensiones de las élites, que comprenden su composición, diferencias ideológicas y relaciones internas. Los datos del PNUD (2005) destacan por una parte, la tendencia a la autoreferencia o "clausura weberiana” de la élite, considerando la preeminencia del origen social en las probabilidades de acceso a los círculos de poder; de otra parte precisan la tendencia a la heterogeneidad interna de las élites en términos ideológicos, destacando cuatro posiciones: progresistas perplejos, conservadores, liberales globalizados y liberales progresistas.

La élite no proviene por igual de todos los grupos sociales, étnicos, religiosos o políticos de un país, sino que su composición revela un sesgo de selección, que contribuye a la reproducción en el poder de quienes ya lo poseen. No hay un único proceso, sin embargo, que intervenga en esta reproducción de los privilegios. En efecto, podemos encontrar mecanismos hereditarios, como ocurre en el caso de la riqueza; asociación entre el origen social y las credenciales necesarias para ingresar a la élite, como ocurre en el caso de la educación; o bien la existencia de mecanismos de selección que discriminan a favor de determinados grupos. Por ello los estudios de la élite deben abordarse estos aspectos y sus interacciones con detención, aún a riesgo de complejizar el análisis.

Los resultados de investigación que se presentan aquí responden a las preguntas que levanta la revisión de estudios anteriores: ¿Cuánta homo-

\footnotetext{
${ }^{3}$ Los resultados de este estudio han sido publicados sólo de forma parcial en medios de difusión, pero se presentan por tener su origen en una investigación académica sistemática. Ver: Santa-Cruz 2004, Santa-Cruz y Guzmán 2008.
} 
geneidad social puede encontrarse en el seno de la élite política y qué alcance tiene en los partidos de distinto signo ideológico? La respuesta a esta pregunta nos llevará a revisar los orígenes sociales de los miembros de la élite y explorar algunos de sus espacios de socialización secundaria, especialmente en la época escolar. ¿Qué tipo de capital social tienen a su disposición los miembros de la élite? Para responder a esta pregunta se cuenta con información relativa a las redes personales de miembros de la élite política, las cuales serán comparadas en términos de tamaño y composición. ¿De qué forma las posiciones en un campo de actores mutuamente referidos condiciona el accionar de los miembros de la élite política? Responder esta última pregunta requiere constituir la élite política como objeto de análisis, poniendo en evidencia el sistema de relaciones entre los actores del dominio político, vale decir la red social que los vincula entre sí, sin utilizar para ello categorías a-priori. La expresión concreta de ello es un mapa de relaciones entre los miembros de la élite.

\section{¿Qué debemos entender por élite política?}

La identificación de los miembros de la élite que juega un papel clave en cualquier estudio, por cuanto habitualmente no existe registro alguno que permita identificarlos. Así, los criterios utilizados para su selección pueden hacer invisibles miembros de la élite o incorporar otros que en realidad no forman parte de ella. En términos generales, la élite política puede definirse como el conjunto de personas que poseen más capacidad para influir en las políticas y actividades del Estado; estas personas, pertenecientes al ámbito público o privado no necesariamente detentan posiciones de autoridad y no siempre poseen visibilidad pública (Putnam 1976, Moore 1979, Highley et al 1991) .

La conceptualización predominante en Chile respecto de la élite sigue la tradición de Pareto, quien propone una definición en la cual la superioridad o primacía de un grupo está basada en la excelencia: la élite corresponde a la posición ocupada por los mejores dentro de cualquier actividad. Desde el momento que existen muchos dominios en la vida social, pueden existir varias élites. Su formulación supone que no hay traslapo ni supremacía entre las diversas élites aunque distingue una élite gubernamental o del poder, definida según los mismos criterios.

En términos operacionales, cuando se sigue una lógica "paretiana”, la interconexión de los integrantes de la élite no es necesaria para su definición, sino que requiere solamente una adecuada caracterización del sistema para identificar a quienes ocupan las posiciones más prominentes en éste. La óptica de este trabajo, sin embargo, busca más bien establecer las raíces sociales del grupo que ocupa posiciones de poder. La élite aquí se

\footnotetext{
${ }^{4}$ Este criterio por lo tanto una definición de poder en términos de influencia política y descarta la coerción.
} 
acercaría más a lo que Mosca denomina “clase política”, dado que la presencia de vinculaciones entre ellos no siempre selecciona a favor de los mejores, a la vez que establece privilegios de herencia. El mismo Mosca ([1896] 1984) se encarga de remarcar que "todas las clases políticas tienden de hecho a convertirse en hereditarias [por] tradiciones y habituamientos a los ambientes”.

Estudiar la élite como clase requiere, entonces, contar con información respecto a la interconexión de sus integrantes, por cuanto constituirían una comunidad de intereses, la cual difícilmente puede lograrse a partir de su caracterización en términos de atributos individuales. Lo que se requiere es un mapa de la élite construido a partir de las relaciones entre sus integrantes. Para ello es que resulta útil el enfoque de redes sociales.

En los trabajos sobre la élite realizados en Chile, su tratamiento ha estado más cerca de una metáfora que de un objeto de estudio al cual pueda aplicarse un análisis sistemático. Para más de un autor, especialmente en la corriente historiográfica, el concepto sirve como punto de apoyo para una argumentación de mayor generalidad, relativa a las lógicas que operan en el sistema político, económico o social (véase por ejemplo Edwards 1982, Pinto 1971, Morris 1967, o Góngora 1986). En los estudios actuales, la caracterización de la élite ha descansado en la descripción de las características individuales de sus integrantes. En verdad, la élite surge desde una red de poder político cuyo análisis debe tratarla como una estructura a la cual puede aplicarse un análisis sistemático a partir del sistema de relaciones entre agentes políticos.

Constituir la élite política como objeto de análisis requiere descubrir el sistema de relaciones entre los actores del dominio político, vale decir la red social que los vincula entre sí, sin utilizar para ello categorías apriori (Wasserman/Faust 1994). Las posiciones que ocupa un actor dentro de la élite sólo pueden caracterizarse adecuadamente utilizando como referencia el sistema de relaciones al cual pertenece. Tal como lo indica el PNUD (2005:182), el poder de la élite "consiste en el ejercicio de la influencia; es decir, en la capacidad de ir conectando distintos ámbitos de acción para desarrollar procesos de conducción hacia donde se desea”. En otras palabras, el poder de la élite no radica en los atributos de sus miembros, sino en la capacidad de éstos para desarrollar estrategias de vinculación social en el ejercicio de la influencia. Un aspecto como este sólo puede analizarse conociendo el tejido social de las relaciones de la élite.

El Informe del PNUD (2005) sobre el poder constituye la primera aproximación a las interconexiones entre miembros de la élite, si bien enfrenta problemas técnicos para la construcción de las redes, insolubles en el marco de una encuesta individual ${ }^{5}$. La encuesta del PNUD generó infor-

\footnotetext{
${ }^{5}$ Entre los analistas de redes no hay acuerdo respecto de las estrategias muestrales que pueden usarse para detectar las conexiones significativas presentes en un grupo cualquiera, pues lo que se debe representar estadísticamente son las vinculaciones y no los individuos.
} 
mación sobre las redes personales de un conjunto de miembros de la élite. La información individual corresponde a un generador posicional de red (Lin 2001), que identifica roles en dominios de la vida social, a partir del cual se construyó un mapa de relaciones. Los datos utilizados corresponden a redes individuales (ego-centradas) los cuales pueden compararse entre sí en términos de su composición, tamaño u otras propiedades, pero no siempre resulta conveniente representarles como una red completa. De hecho, las relaciones indirectas -esto es por medio de una posición en una escala- son puramente hipotéticas y no representan necesariamente las relaciones entre integrantes de la red.

La representación de estos datos como un sociograma y el cálculo de sus propiedades -como lo hizo el PNUD en su informe- no resulta apropiado por cuanto la información de "relaciones" corresponde en realidad a coincidencias en una escala de respuesta. Se trata en verdad de una representación multidimensional de la escala subyacente, que reconoce proximidades por pautas de respuestas semejantes, antes que un sociograma. Los datos que utiliza el presente estudio si bien son de redes personales, superan este problema porque han identificado a los integrantes de las redes personales.

\section{La identificación de la élite}

Los intentos por diferenciar empíricamente la élite están generalmente limitados por una definición que no solamente precede a su estudio, sino que resulta inmodificable. De esta forma, la élite no puede ser más ni menos de lo que el investigador ha decidido al comenzar su estudio. Este tipo de identificación operacional de los miembros de la élite se convierte además en la definición de su estructura interna, lo cual hace su autonomía o interconexión verdaderas por postulación. Berkowitz (1982) argumenta que las estrategias de identificación de las élites inciden en los resultados de las investigaciones, de forma que la identificación de la élite basada en la participación en decisiones tiende a favorecer resultados afines con el enfoque pluralista, mientras que las basadas en la reputación producían resultados contrarios.

Idealmente, la identificación empírica de la élite política debe considerar tres criterios: el desempeño de posiciones formales de autoridad, la reputación de poseer poder y la incidencia en procesos de toma de decisiones (Putnam 1976, Berkowitz 1982, Knoke 1990). La identificación de posiciones formales de autoridad generalmente no reviste mayor complicación, salvo la definición sobre la cantidad de sectores y el nivel de jerarquía $^{6}$. El prestigio como criterio de identificación de los miembros de la

La búsqueda de distribuciones estadísticas adecuadas para estudiar las vinculaciones entre un conjunto de individuos se encuentra en sus primeros pasos.

${ }^{6}$ Por limitaciones de recursos, este proyecto ha considerado principalmente los diputados, aunque desde el punto de vista de su autoridad formal, también senadores, ministros de estado, altos miembros del poder judicial o embajadores pueden considerarse parte de la élite política. En la segunda ola de entrevistas se incluyeron tanto diputados que se convir- 
élite requiere utilizar medidas confiables, de las cuales existe un amplio rango. Finalmente, la participación en procesos de toma de decisiones es la más difícil de cumplir, porque requiere conocer a fondo los casos, dado que pueden participar personas de bajo perfil público -expertos, asesores, financistas, lobbystas, entre otros. Además, los estudios de toma de decisiones pueden cubrir ámbitos específicos de la política pública por lo que no resultan adecuados para contrastar la tesis de que existe una élite política nacional (Highley et al 1991).

Los estudios sobre élite chilena privilegian la presencia en posiciones formales de autoridad para establecer su composición (Joignant \& Navia 2003; Cordero 2007, Alcántara-Sáez \& Llamazares-Valduvieco 1997)7 . El estudio de Santa-Cruz (2004) consideró quienes ejercían posiciones de autoridad formal en diversos ámbitos, de los cuales seleccionó aleatoriamente un grupo de entrevistados. Por su parte Hardy (2005) operacionaliza la élite basada en el ejercicio de posiciones de autoridad formal en el Estado, los partidos políticos o las organizaciones sociales. El estudio del PNUD (2005) también considera autoridades en diversos ámbitos, a lo que agrega una selección reputacional de entrevistados, basada en el juicio de expertos. Una vez identificados, se les caracteriza en términos de su origen, profesiones, orientaciones valóricas o ideológicas, etc.

La limitación más obvia del criterio de selección por posición de autoridad formal es que puede incluir personas que no tienen incidencia en las decisiones, pero es aún más problemático el que no considere quienes tienen influencia indirecta en la decisión a través de su relación con las autoridades. Aún así, algunos autores homologan “clase política” con el ejercicio de un cargo parlamentario, por la alta probabilidad de que su sustento económico se origine en el ejercicio de la actividad política (AlcántaraSáez \& Llamazares-Valduvieco 1997). En los casos que se utiliza el juicio de expertos, la calidad de la muestra depende de la eficacia de los expertos que revisan y deciden sobre la muestra ¿qué sectores sociales representan? ¿entienden por élite política o por poder lo mismo que los investigadores? ¿cuán amplia es la información que poseen?

Aparte de las dificultades para reconocer los miembros de la élite, la principal complicación operativa es que sus miembros no están disponibles para ser estudiados. No es sencillo entrevistarlos, porque prefieren dedicar su tiempo a cuestiones que estiman más valiosas que responder las preguntas de un cuestionario académico. La documentación pública sobre

tieron en senadores como seis senadores que entraron al parlamento en tal condición.

${ }^{7}$ De acuerdo con el criterio de autoridad formal, Sebastián Piñera o Joaquín Lavín, por ejemplo, no habrían sido considerados miembros de la élite política al momento de realizar el estudio, dado que no ostentaban cargo político alguno. El cuestionario de la segunda ola de entrevistas incluyó la pregunta “ $\dot{\boldsymbol{A}}$ A su juicio quiénes son las dos o tres personas con mayor poder o influencia en este ámbito?”, que consideraba 12 campos de poder. Las personas mencionadas generalmente ocupaban posiciones formales de poder o bien eran de frecuente mención en los medios de comunicación. 
integrantes de la élite es limitada y no siempre confiable, pues muchas veces está destinada explícitamente a construir una imagen del personaje.

\section{Datos del estudio}

La información que sustenta los análisis fue generada por medio de una encuesta de redes en dos olas, que permitió entrevistar 51 diputados y seis senadores que han ejercido entre 1990 y 2005. Cada uno de ellos respondió un cuestionario que en lo pertinente para este análisis corresponde a una lista de contactos personales en diversos ámbitos de la vida social, política, cultural y económica. Se les pidió a los entrevistados que mencionaran aquellos que conocían desde antes de ejercer como parlamentarios, por lo cual los datos reflejan la composición de las redes sociales con que contaban estos parlamentarios antes de integrarse en el cuerpo de representantes. (Por supuesto, con las distorsiones que supone la memoria). No todos los entrevistados completaron el cuestionario en lo referido a redes sociales -más aún, 52 contactados no quisieron ser entrevistados- lo cual incide en el tamaño de sus redes, incluyendo dos que no respondieron preguntas de la sección redes personales; por ello, los datos presentados corresponden a 50 diputados y seis senadores.

La opción por la encuesta de redes permite superar la limitación de los estudios actuales de la élite que la definen a partir de las posiciones formales de autoridad. Aún cuando la muestra tiene éstas como punto de partida introduce criterios de prestigio e incidencia a través de la vinculación con personas de otros círculos sociales, que no ocupan necesariamente posiciones formales de poder; contactos que pueden resultar clave para asegurar la posición de los representantes formales. Una palabra de cautela: el rol del entrevistado en cuanto parlamentario no refleja totalmente su posición en la élite dado que, según el período de referencia, puede ser también empresario, dirigente político, ministro, alcalde. De esta forma, los roles deben entenderse como indicaciones que sólo cobrarán sentido al momento de analizar la red. Además, pueden existir relaciones entre las personas mencionadas que no fueron registradas en el estudio, que considera principalmente relaciones sociales previas al ejercicio parlamentario.

La estrategia de muestreo tiene como punto de partida las posiciones de autoridad formal, restringidas en la primera ola de entrevistas a una muestra de diputados. El interés analítico en los diputados, reside en ciertas cualidades que favorecen el análisis de su estructura social, tales como el mayor número de integrantes (120 contra 38 senadores), su mayor renovación producto de ejercicios de cuatro años, por constituir muchas veces un paso previo al Senado y vincularse crecientemente con la participación en cargos de responsabilidad estatal o ejecutiva en el gobierno ${ }^{8}$.

${ }^{8}$ Desde 1994, el Proyecto Elites Parlamentarias Latino-Americanas (PELA) dirigido por Manuel Alcántara-Sáez ha generado valiosa información de los diputados en ejercicio rela- 
Durante el año 2007 se llevaron a cabo 30 entrevistas con diputados sobre la base de una muestra estructural que combina antigüedad en el ejercicio, región que representan y partido políticos de pertenencia. El año 2008, una segunda ola de entrevistas alcanzó otros 22 diputados y seis senadores $^{9}$. El nivel de saturación de la segunda ola, correspondiente a la proporción de contactos ya mencionados en la primera ola, alcanzó 17\% lo cual indica que el campo al cual pertenecen los entrevistados está lejos de constituir un sistema cerrado. La muestra total comprende 57 parlamentarios en diversas condiciones de ejercicio.

\section{Distribución de los parlamentarios entrevistados según último partido de militancia ${ }^{10}$ y condición actual de ejercicio}

\begin{tabular}{|l|c|c|c|c|}
\hline Partido & $\begin{array}{l}\text { Diputado } \\
\text { en ejercicio }\end{array}$ & $\begin{array}{l}\text { Diputado } \\
\text { Retirado }\end{array}$ & Senador (*) & Total \\
\hline PDC & 6 & 11 & 4 & 21 \\
PS & 6 & 1 & 3 & 10 \\
PPD & 4 & 2 & 1 & 7 \\
PRSD & 1 & & 1 & 2 \\
RN & 6 & 2 & & 8 \\
UDI & 8 & 1 & & 8 \\
Independiente & & 17 & 9 & 57 \\
\hline Total & 31 & 1 \\
\hline
\end{tabular}

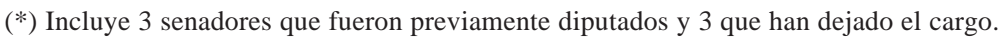

En la muestra de entrevistados predominan los parlamentarios en ejercicio de su cargo (31 diputados y 6 senadores). Del total de entrevistados, los más accesibles resultaron ser los parlamentarios de la Concertación, comprendiendo 40 entrevistados en total, con predominio del PDC (21) y el PS (10). En la Alianza se cuenta con 16 entrevistados, repartidos igualmente entre RN y UDI. También se entrevistó un diputado independiente.

tiva a origen y contexto social, valores políticos, actitudes y estilos. Los datos, sin embargo, no incluyen información relacional. http://americo.usal.es/oir/elites/

${ }_{9}^{9}$ Agradecemos la disposición de todos quienes respondieron al cuestionario, agregando así una nueva dimensión al conocimiento público de la actividad parlamentaria. El estudio también generó información sobre las redes de otros 70 contactos de los parlamentarios que no se consideran en este análisis, relevantes por su prestigio, capacidad de articulación o círculo de pertenencia; ellos incluyeron ministros, alcaldes, senadores y dirigentes de partidos. ${ }^{10}$ Las siglas de los partidos usadas en este artículo corresponden a las siguientes formaciones: PDC: Partido Demócrata Cristiano; PS: Partido Socialista de Chile; PPD: Partido Por la Democracia; PRSD: Partido Radical Sociademócrata; RN: Renovación Nacional; UDI: Unión Demócrata Independiente 
Entre los diputados que ya no ejercen cargos parlamentarios se advierte un claro predominio DC (11 de 17, sin contar los senadores).

La muestra corresponde mayormente a diputados y senadores en ejercicio. En la práctica, los datos, sin ser definitivos reflejan estructuralmente la proporcionalidad entre la región de pertenencia, la antigüedad en el cargo y el bloque político de todos los diputados. El tratamiento de los datos se hará de forma conjunta para diputados y senadores, tanto porque la información provista corresponde a vinculaciones existentes con anterioridad al ejercicio parlamentario, como porque de existir alguna diferencia entre ellos ella debiera manifestarse al momento del análisis.

Los diputados entrevistados en la primera ola mencionaron sus contactos en 32 círculos sociales. El número de menciones de cada contacto para el total de diputados entrevistados se interpreta generalmente como un indicador de prestigio, con lo cual la segunda ola de entrevistas introdujo el criterio de reputación en la identificación de la élite (Knoke 1990, Moore 1979). Tomando en cuenta el tipo de entrevistados y la experiencia de la primera ola, en la segunda ola de entrevistas se aplicó un cuestionario más breve y amigable. Los 32 círculos sociales de la primera se redujeron a 12, evitando el detalle en las menciones; por ejemplo, en lugar de mencionar grandes empresas en varios sectores de actividad económica como se hizo en la primera ola, se prefirió la formulación genérica "grandes empresas". Igualmente se redujeron las preguntas biográficas que poseían menos relevancia para los entrevistados en la segunda ola.

Un análisis descriptivo de los efectos del instrumento sobre el tamaño de las redes personales permite establecer que éste no afectó mayormente el número de contactos, pero si el tamaño de las redes, produciendo redes más redundantes en la segunda ola. En efecto, el tamaño de cada red personal en términos de contactos resultó muy similar entre ambas olas, alcanzando 44 en la primera y 43 en la segunda. Sin embargo, el número de contactos únicos en cada ola resultó ser menor en la segunda ola, pues nombraron 21 contactos, por contraste con los 29 mencionados en la primera. Visto de otra forma, en la segunda ola hay dos círculos sociales asociados con cada nombre, mientras que en la primera hay $1,5^{11}$. Un análisis estricto de los efectos del instrumento sobre las características de las respuestas sobre redes personales requeriría separar los efectos del número de preguntas, el fraseo de éstas, la disposición del entrevistado a responder las preguntas, sus características personales y posición en el campo de pertenencia. Todo ello escapa a los objetivos de esta presentación, más centrada en los resultados del estudio.

\footnotetext{
${ }^{11}$ Ello seguramente tiene relación con el número de círculos considerados en cada ola -32 en la primera y 12 en la segunda - pues la diferencia es más pequeña en el tamaño de la red que en el número de contactos por círculo. Dado que la muestra de entrevistados no es aleatoria resulta no es posible establecer si hay una diferencia estadística significativa.
} 


\section{Resultados: origen y estructura de la élite política}

El ejercicio de la actividad parlamentaria, junto con representar a los ciudadanos requiere establecer relaciones de confianza que sustenten compromisos y acuerdos de largo plazo en decisiones sobre asuntos públicos. Sea que esta confianza provenga de valores adquiridos en una socialización común o de interacción social repetida en diversos contextos, ello pone en foco el efecto de las relaciones sociales sobre la capacidad de los parlamentarios para representar intereses ciudadanos de forma independiente a los grupos sociales a los cuales pertenecen.

La investigación sobre élites económicas ha establecido que las relaciones de parentesco constituirían la columna vertebral de los grupos de poder, que opera como una red abierta a través de los matrimonios (White 1994, Adler-Lomnitz \& Pérez 1987, Zeitlin \& Ratcliff 1988, Alcántara-Valverde \& Casasola-Vargas 2002, Stabili 2003). De allí que se suponga que la familia opera como un punto de apoyo clave al momento de establecer relaciones de confianza. El grueso de la evidencia histórica disponible, sin embargo, corresponde principalmente a los siglos XVIII y XIX, aunque se ha mostrado la incidencia de la familia en la designación en posiciones de la burocracia pública hasta comienzos del siglo XX. Cabe preguntarse entonces si el parentesco sigue ocupando una posición central en la conformación de la élites.

En el contingente de diputados que ha ejercido entre 1990 y 2005 la consanguinidad, si bien presente, está lejos de constituir un rasgo distintivo. Se ha llegado a argumentar el carácter particular de la élite política, que tendría mayor permeabilidad que otros sectores, lo que se expresa, en un un origen social heterogéneo de sus componentes (Thumala 2007). Por su parte, la sociología ha documentado ampliamente, cómo a lo largo de los últimos siglos, las relaciones de parentesco han dejado de constituir la base exclusiva de las relaciones de confianza, para ser reemplazadas progresivamente por la amistad (Giddens 1990). Por ello, en nuestra investigación suponemos que la base social de la élite política debe buscarse más bien en círculos de sociabilidad secundaria, esto es en amistades, instituciones, y clubes de diverso tipo.

\section{Origen social de los Diputados}

La descripción socio-demográfica de los integrantes de la élite permite poner en contraste las afirmaciones acerca de un origen social homogéneo. La similitud de origen social indicaría tanto que los representantes son reclutados desde un mismo círculo social, como que comparten valores y actitudes propios de ese sector. El origen común indicaría baja "integración vertical” es decir, menor arraigo en los diversos grupos que componen una sociedad. De forma similar, el tiempo de permanencia en el cargo puede indicar una tendencia a consolidar posiciones por bajo recambio. A continuación se revisan tiempo de ejercicio, edad, escolaridad y establecimientos donde realizaron sus estudios. 
La composición de la Cámara de Diputados comprende dos representantes por cada uno de los 60 distritos electorales en que se encuentra dividido el país. Durante los cinco períodos que comprenden los años 1990 a 2005 han ejercido un total de 289 parlamentarios (seis más si se considera quienes reemplazaron a diputados que cesaron en el ejercicio su cargo por muerte u otra causa), lo cual involucra una renovación mediante elecciones de 52\% del cuerpo a lo largo del período. Este primer dato indica competitividad en el acceso, expresada por una tasa comparativamente alta de renovación. De todas formas, no debe descuidarse que 91 de los 289 (22\%) diputados han ejercido por tres o más períodos. Un elemento adicional lo entrega la edad de los diputados.

La edad promedio actual se encuentra entre los 48 y 49 años y se mantiene así desde 1998, sin cambios marcados respecto de los dos primeros ejercicios, cuando se ubicaba alrededor de los 45 años. Ello es reflejo de una sociedad cuya población envejece, no solamente un resultado de parlamentarios que permanecen en sus cargos. No se puede afirmar, por lo tanto, como rasgo definitivo, que los parlamentarios envejecen ejerciendo sus cargos, sino que más bien circulan y se renuevan. La estabilidad en el promedio de edad, a pesar de la permanencia de algunos de ellos por varios períodos, refleja la permeabilidad de las barreras de entrada a la incorporación de políticos relativamente jóvenes. El Gráfico 1 presenta las distribuciones de edad de los diputados al comenzar cada ejercicio entre 1990 y $2006^{12}$.

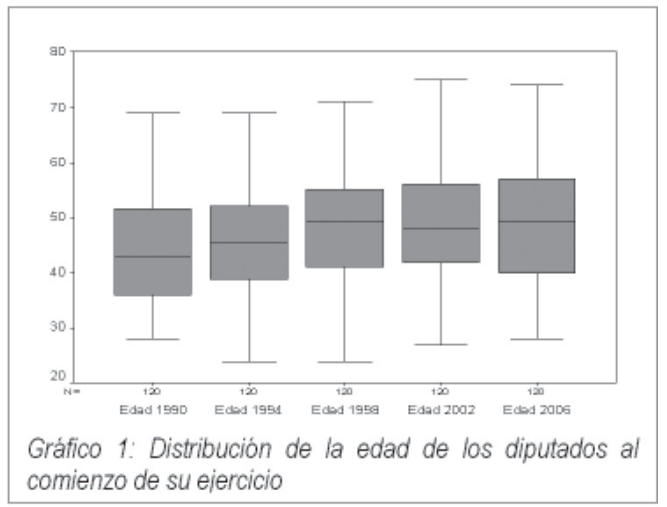

\footnotetext{
${ }^{12}$ La gráfica de cajas con patillas que se presenta posee los siguientes elementos: una caja cuyo largo corresponde a la distancia entre cuartiles; la línea al interior de la caja marca la mediana de la distribución. De esta forma, la caja comprende el $50 \%$ de los casos en la distribución, mientras que la posición de la mediana permite identificar la simetría o la dirección del sesgo. El largo de las patillas corresponde a 1,5 veces la distancia intercuartílica. Los valores sobre o bajo la patilla se identifican con signos convencionales para distinguir outliers y extremos, que no existen en este caso; una indicación de que la variación de edades se encuentra dentro de rangos razonables.
} 
Polis, Revista de la Universidad Bolivariana, Volumen 9, $N^{\circ}$ 26, 2010

\section{Escolaridad}

A medida que el foco se aproxima a la élite política tiende a operar lo que Putnam (1976) llama la "ley de la desproporción creciente”, vale decir que aparecen sobre-representadas las categorías socialmente más privilegiadas, y por ello escasas en el conjunto de la población. Tal es el caso cuando llegamos a la escolaridad. El Gráfico 2 presenta el nivel de años de escolaridad promedio de la población total y los diputados desde 1961 hasta la actualidad ${ }^{13}$.

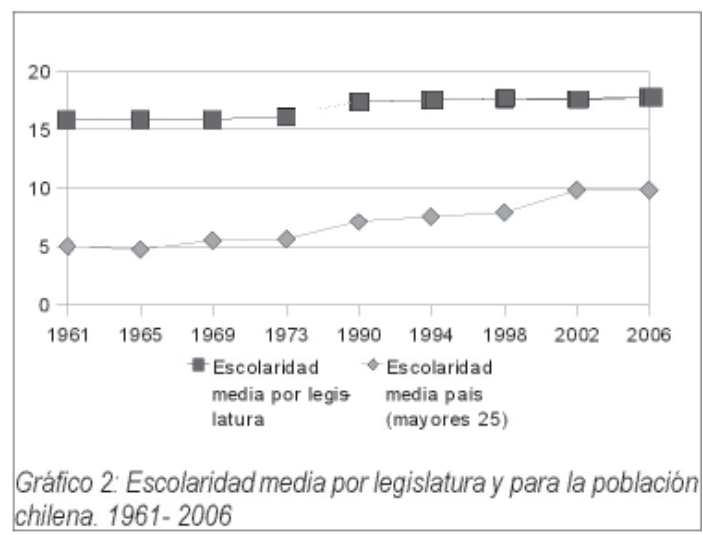

La escolaridad de los diputados siempre ha sido más alta que el promedio de la población. A lo largo del tiempo la brecha de escolaridad ha ido disminuyendo, porque si era de 3,2 veces en 1961, actualmente es de 1,8 veces. Ello resulta dos efectos combinados. De una parte, el incremento en las oportunidades de acceso al sistema escolar para la población en general, a partir del esfuerzo de inversión pública realizado desde los años 1960. Otra parte corresponde a un "efecto techo" pues en rangos más altos de escolaridad los incrementos son menores. Por lo mismo, en lugar del promedio de años de estudio, puede resultar más claro comparar el acceso proporcional a los niveles más altos de escolaridad. El Gráfico 3 presenta los datos de escolaridad universitaria completa para los diputados y la población mayor de 25 años.

\footnotetext{
${ }^{13}$ Fuentes: Escolaridad Diputados en los años 1961-1973 Cordero 2007. Escolaridad diputados 1990-2006 según Reseña Biográfica de Diputados. Datos nacionales 1961-1973 Barro et al, 2000, Encuesta Casen para 1990-2006.
} 


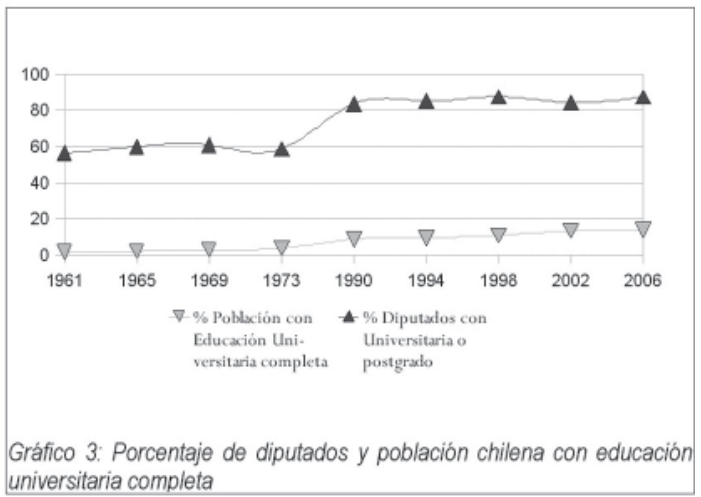

La educación universitaria aparece claramente sobre-representada entre los diputados. Mientras 87\% de los diputados tiene educación universitaria completa (y la cuarta parte de ellos postgrados), en Chile menos del $15 \%$ de la población posee educación universitaria completa. En otras palabras, entre los diputados hay más de seis veces graduados universitarios que en la población general. Entre los diputados se aprecia un salto marcado en el acceso a la educación universitaria entre la década de 1960 y la actualidad; que en la población chilena muestra un incremento menos acentuado, si bien sostenido. Los diputados comprenden una parte de la población que ha tenido acceso a altas oportunidades de escolarización.

\section{Espacios de socialización. Colegios y universidades}

¿La alta escolaridad de sus integrantes refleja un acceso por mérito o tiene su base en un origen social privilegiado? Una forma de aproximarse a ello consiste en revisar el tipo de educación al cual tuvieron acceso. Si los diputados provienen de la educación pública y a través de ella alcanzaron los grados más altos de calificación, debe suponerse que ello debe más a méritos propios que a privilegios de cuna. En el Gráfico 4 (página siguiente) se aprecia la evolución de la proporción de diputados que se educaron en la enseñanza pública y la educación privada ${ }^{14}$.

\footnotetext{
${ }^{14}$ La línea continua sirve solamente como guía en el caso de los diputados pues se trata de promedios al comienzo de cada ejercicio.
} 


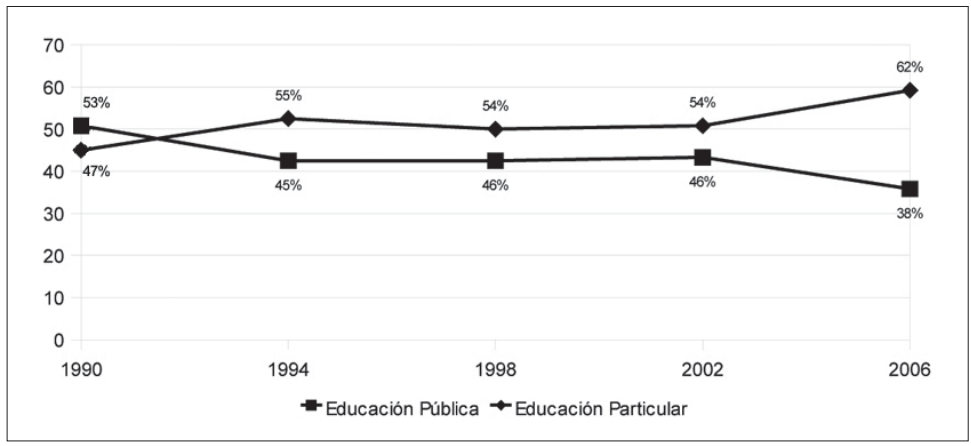

Gráfico 4

Hay un descenso sostenido de los diputados que provienen de la educación pública quienes pasan de 53\% en 1990 a 38\% en 2006. Por otra parte, se aprecia el incremento de los diputados que cursaron su enseñanza media en la educación particular -alrededor de 85\% de ellos en establecimientos de orientación católica. Los establecimientos de orientación católica, de hecho, incrementan su peso entre los diputados desde 39\% a 49\% entre 1990 y 2006. Ya en el ejercicio de 1994 los diputados educados en colegios privados superaron a los provenientes de la educación pública. La proporción se mantuvo relativamente estable hasta el ejercicio de 2002; no obstante, $62 \%$ de los diputados elegidos para el ejercicio que se inicia el 2006 provienen de colegios particulares.

La pauta de variación observada en la escolaridad de los diputados refleja un fenómeno estructural propio del sistema educacional chileno. Desde comienzos de los años 1980, la educación pública fue cediendo terreno a la educación particular en cuanto a calidad y resultados. Ello constituye una de las grandes fuentes de inequidad en el país, pues quienes no cuentan con los recursos para financiar una educación privada, se ven frecuentemente librados a una educación de baja calidad. La respuesta a la pregunta acerca de qué indica la mayor escolaridad universitaria de los diputados es que ella refleja, entre los representantes populares, el creciente peso de la población que ha tenido las mejores oportunidades de educación como resultado de contar con los recursos para financiarla.

Al poner el foco sobre los establecimientos de los cuales proviene el mayor número de diputados se aprecia que ellos se reparten de manera pareja entre públicos y privados católicos ${ }^{15}$. En el período considerado, el Colegio San Ignacio es el establecimiento por cuyas aulas pasó el mayor número de diputados (15, de los cuales 10 pertenecen a la Concertación).

\footnotetext{
${ }^{15}$ Se consideran los establecimientos por separado, lo cual opaca el efecto que tienen las congregaciones católicas que administran establecimientos en diferentes regiones o bajo diferentes denominaciones.
} 
Le sigue el Internado Nacional Barros Arana con 11 diputados (verdadera cantera Concertacionista). Llama la atención también el número relativamente alto de diputados que se formaron en la Escuela Militar (6). El promedio de edad de los diputados que estudiaron en la educación pública es más alto (50) que quienes lo hicieron en la privada (46), por lo que se puede suponer que comience a declinar su peso, como ha sido el caso en el país para el conjunto de la educación pública.

El predominio de estudios en establecimientos particulares católicos coincide con aquellos en los cuales estudia la élite económica (Thumala 2007). Ello es absolutamente claro para los responsables de estos establecimientos; así por ejemplo, la página de presentación de uno de los administradores -de cuyos diversos establecimientos provienen 10 diputadoslo dice con todas sus letras: "La Congregación del Verbo Divino, desde 1900, educa a los grupos dirigentes del país”. La coincidencia en los mismos colegios durante su enseñanza de los futuros líderes económicos y políticos puede llevar hipotetizar acerca de la relevancia que pueden adquirir los lazos establecidos en la época escolar En la actualidad, no obstante, los lazos de la escolares tienen escasa relevancia por comparación con los establecidos en la época universitaria. Puede decirse que los parlamentarios actuales desarrollaron su interés por la política en la enseñanza media, para concretarla en militancias específicas durante su época universitaria, momento en el cual ya habían perdido contacto con la mayor parte de sus compañeros de colegio (Espinoza \& Madrid 2010).

En cuanto a la enseñanza superior, relevante pues cerca del 90\% de los parlamentarios poseen estudios universitarios, la Universidad de Chile y la Universidad Católica han acogido $60 \%$ de ellos. Vale decir que los miembros de la élite parlamentaria estudian en Santiago, y muchos siguen acudiendo a sus aulas desde regiones, una vez que completan su enseñanza media. En ambas universidades se establece un campo político conformado por dirigentes estudiantiles y partidarios mutuamente reconocidos; vale decir, nadie que está en política universitaria pasa desapercibido para el resto de los militantes, sean o no de su partido. En las entrevistas, muchos de los parlamentarios revelaban conocer la trayectoria de dirigentes y parlamentarios de otros partidos desde su época de estudiantes, incluso de los pertenecientes a otras universidades.

En cuanto a las universidades de regiones cabe destacar la disminución que experimenta la Universidad Católica de Valparaíso, institución que pasa de 9 a ningún parlamentario, en el período considerado. En contraste, la Universidad de Concepción mantiene una presencia constante cercana al $10 \%$ de parlamentarios en todos los ejercicios. Finalmente debe resaltarse el incremento en la participación de las universidades privadas, que pasa de 3\% en 1994 a 12\% en 2006. Ello refleja sin duda el cambio en la composición de la oferta de educación superior en el país, a la vez que permite suponer que las universidades privadas desarrollan en sus estudiantes orientaciones cívicas y de responsabilidad social que se concretan en el ejercicio político. 
En suma, junto con un cambio generacional se aprecia una creciente homogeneización en el origen social de los parlamentarios. Se trata de una minoría con alta escolaridad, que provienen crecientemente de colegios privados católicos y que han cursado sus estudios superiores en las mayores universidades de Santiago.

\section{El Capital social de los diputados}

Los diputados entrevistados respondieron preguntas acerca de su trayectoria social, política y campañas, junto con mencionar los contactos que poseían en diversos círculos sociales, antes de ser elegidos parlamentarios. Un indicador del volumen de capital social puede establecerse por medio de la cantidad de contactos que posee cada parlamentario, pues mientras mayor es el volumen de contactos, mayor es la probabilidad que estén disponibles recursos escasos o de lograr acceso a diversos círculos sociales (Lin 2001).

Los parlamentarios entrevistados mencionaron 2408 contactos, vale decir unos 44 en promedio ${ }^{16}$. Algunos de los contactos de los diputados eran mencionados solamente por uno de los entrevistados, mientras que en otros existía coincidencia. Las redes de los diputados remiten a un conjunto de contactos compartidos (63\%), pero también a contactos exclusivos. Compartir contactos puede tomarse como una indicación de cierre en esta red, dado que prácticamente dos tercios de los contactos aparecen traslapados entre una y otra red personal. Visto de otra forma, los parlamentarios entrevistados están conectados entre sí a través de conocidos comunes. La pauta de conectividad en la red requiere un análisis más detallado a fin de establecer si estos contactos expresan situaciones de horizontalidad -o competencia en el acceso a círculos sociales- o bien de jerarquía, es decir dependencia común de un mismo contacto.

Pese a la alta conectividad, una característica interesante de las redes personales es la escasa redundancia de los contactos a través de los diversos círculos sociales. Por ejemplo, los roles de empresario, miembro de un grupo económico y dirigente gremial pueden superponerse en una misma persona; no obstante, los entrevistados normalmente mencionaban distintos nombres en cada categoría. Vale decir, los diputados poseían, antes de su ejercicio, acceso a través de contactos personales a una cantidad significativa de círculos sociales, a través de más de un canal.

Hay 888 contactos no compartidos, vale decir como promedio unos 16 por cada red (37\%), lo cual indica acceso exclusivo a círculos sociales.

\footnotetext{
${ }^{16}$ Se consideran ambas olas de entrevista en conjunto. Los cálculos se realizan sobre el total bruto de menciones, que incluyen contactos no bien identificados (tales como: voluntarios, un amigo empresario, directores de medios locales, etc.) que no fueron considerados posteriormente en el análisis de redes, que requiere menciones unívocas.
} 
El examen más detallado de los contactos exclusivos permite apreciar que éstos corresponden principalmente a relaciones hacia el interior de sus partidos políticos (28\%). Básicamente se trata de militantes que les apoyan durante sus campañas y que, una vez elegidos, mantienen su presencia en los distritos; constituyen por lo tanto, cuerpos de apoyo en gran medida subordinados. Siguen los contactos familiares o sociales informales (12\%), gremiales e intelectuales, ambos con $11 \%$. Este tipo de vinculaciones fueron mencionadas como respuesta a preguntas específicas del cuestionario (por ejemplo, familiares que fueran militantes) y no poseen mayor relevancia en los relatos espontáneos de los entrevistados. De forma similar, las relaciones con intelectuales o artistas tienen una diversidad tal, que comprenden desde el baladista Alberto Plaza hasta el rector de la Universidad de Chile. La presencia de los líderes gremiales y sindicales entre los contactos exclusivos es una indicación de la dispersión del campo social, donde existen múltiples interlocutores.

En suma, los contactos exclusivos de cada parlamentario, que corresponden a la disponibilidad de relaciones sociales no compartidas, en realidad constituyen un capital relacional valioso sobre todo por la calidad de los recursos disponibles en cada contacto, más que por la exclusividad del círculo social. Los contactos proveen apoyo continuo al potencial parlamentario, prácticamente desde sus inicios: la familia provee de recursos económicos, así como apoyo organizacional y afectivo, mientras que los militantes permiten hacer operativa la gestión de campañas y la vinculación hacia los distritos.

Los ámbitos en los cuales los parlamentarios poseen contactos se presentan agrupados en 10 categorías para examinar con mayor claridad la composición de las redes sociales, según los partidos políticos a los cuales pertenecen los entrevistados. La identificación del ámbito se refiere a la asignación que hace el entrevistado, por lo cual un mismo contacto puede haber sido integrado a diversas categorías; el análisis de estos traslapos se retoma posteriormente. El Gráfico 5 permite apreciar la distribución de los contactos en 10 círculos sociales. Para conveniencia de lectura, los contactos hacia el sistema político se presentan en gradación de grises, mientras que los contactos hacia el mundo social se presentan achurados sobre fondo blanco.

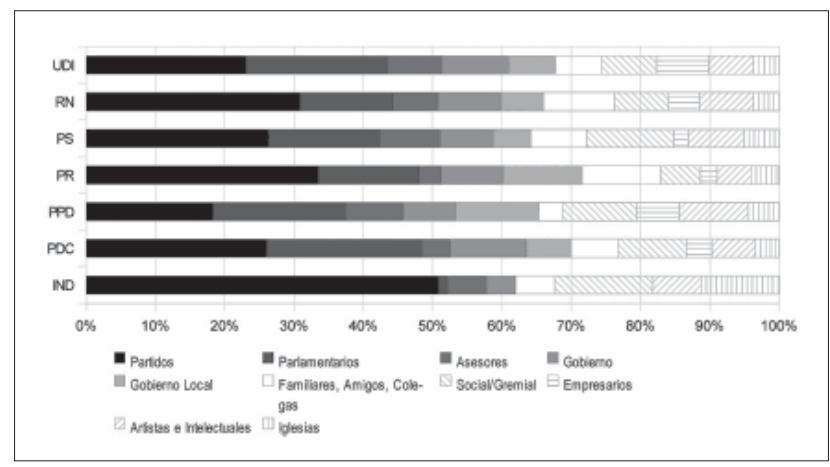

Gráfico 5 
Las redes personales de los diputados muestran alta dedicación a los contactos propios de su campo de acción. Las categorías de mayor peso en las redes personales de los diputados son las referidas a contactos con dirigentes o militantes partidarios (26\%), seguida por los contactos con otros parlamentarios (19\%). Si agregamos a lo anterior los contactos con asesores (6\%), el gobierno central (9\%), intendentes, alcaldes y servicios públicos autónomos (7\%), el conjunto de contactos correspondientes al sistema político alcanza en promedio $68 \%$. El rango es relativamente cercano entre partidos, variando entre un mínimo de 64\% entre los Socialistas a un máximo de $72 \%$ entre los Radicales.

El peso de los contactos que poseen todos los parlamentarios hacia el interior de sus partidos converge con evidencia cualitativa relativa a la relevancia que posee dominar posiciones de poder partidario con el fin de asegurar su selección como candidatos (FLACSO 2007). En la actualidad, una función clave de los partidos políticos reside en el poder que poseen para definir candidatos, dado que bajo las actuales reglas electorales, la designación en un distrito favorable, de no mediar contratiempos equivale prácticamente a la elección. En la medida que los miembros de las redes personales corresponden a personas conocidas antes de ocupar el cargo parlamentario, podemos apreciar que ya como candidatos poseen vínculos fuertes con militantes y dirigentes que les apoyan primero en "la interna” y luego durante la campaña. Más aún, como se veía anteriormente, muchos de estos vínculos son exclusivos de cada parlamentario, constituyendo de esta forma un soporte crucial para su actividad política.

Los vínculos hacia otros parlamentarios, también poseen alto peso en todos los partidos, especialmente en el PDC (23\%), la UDI (21\%) y el PPD (19\%). La existencia de vinculaciones previas al ejercicio del cargo muestra que los parlamentarios pertenecen a un campo en el cual han estado en contacto a través de diversas actividades que comprende su carrera política antes de llegar al parlamento. De hecho, sólo 20 vínculos exclusivos llevan a parlamentarios que ya no están en ejercicio (9 de ellos que ejercieron hasta 1973) y otros 26 a parlamentarios en ejercicio (cinco de ellos senadores). La funcionalidad de los vínculos exclusivos con otros parlamentarios es menos interpretable que los contactos con militantes, aunque puede hipotetizarse que contactos personales previamente existentes pueden sustentar el establecimiento de acuerdos y fortalecer la capacidad de acción conjunta ${ }^{17}$.

Los contactos hacia el mundo social exhiben algunas pautas dignas de destacar. Socialistas y miembros del PPD destacan en sus conexiones hacia el mundo social que alcanzan $13 \%$ y $11 \%$, respectivamente; mientras que en el PR se encuentra el nivel más bajo (6\%). Otro aspecto interesante es el alto peso que poseen los contactos con empresarios entre los diputa-

\footnotetext{
${ }^{17}$ También es posible que ello sea un sesgo de la muestra, por la opción de saturar algunos distritos, aunque ello requiere análisis detallados que desviarían el foco del artículo.
} 
dos de la UDI (8\%), seguido por el PPD (6\%) y RN (5\%); en otros partidos de la Concertación los contactos con empresarios son más escasos, especialmente en el PS y PR (2\%). Es posible que haya un efecto de respuestas "políticamente correctas" entre estos parlamentarios dado que, por su ideología, en ellos cobra mayor relevancia mantener autonomía respecto a los intereses económicos ${ }^{18}$. Finalmente, los contactos hacia iglesias, especialmente la Católica, alcanza un nivel bajo (4\%) de forma pareja en todos los partidos.

En suma, las redes personales de los diputados poseen una variedad de formas de capital social, sin que sea clara una forma predominante. En la configuración general de las redes personales de los parlamentarios entrevistados parecen operar simultáneamente dos principios: una cierta tendencia al cierre por jerarquización, que se balancea con baja redundancia de contactos. Las redes poseen cierto cierre vertical focalizado en personas prestigiosas -principalmente senadores- pero también ofrecen a los entrevistados ventajas de intermediación propias de configuraciones poco redundantes (Burt 2005). En las redes de baja redundancia, que Burt (2005) denomina «empresariales», quien ocupa una posición central controla la vinculación entre círculos sociales de otra forma desconectados entre sí. Las ventajas de intermediación han sido asociadas con ganancias materiales, control de recursos, así como mayor creatividad (Burt 1992). Claro que la centralidad del entrevistado no siempre compensa el prestigio del miembro de la red, por lo que su operación puede ofrecer amplio espacio de interacción estratégica.

El número de ámbitos a los cuales tienen acceso los parlamentarios es generalmente mayor que la cantidad de miembros en su red, dado que una misma persona puede operar como canal de acceso múltiple. Los lazos mencionados por los entrevistados no son múltiples, sino especializados, apreciándose un equilibrio en los canales de acceso a cada ámbito. Tampoco se aprecia redundancia de contactos en las redes, esto es diversos contactos que lleven a un mismo ámbito, lo cual tendería a reducir su eficacia global. Especialización de los lazos y baja redundancia en las vinculaciones revelan una estructura que favorece la gestión eficiente de los vínculos. No obstante lo anterior, se aprecian ciertos nodos sobre los cuales convergen muchas nominaciones, lo cual indica tanto su centralidad, como la competencia en el acceso entre varios integrantes de la red.

Aclarar el peso de cada uno de estos aspectos requiere mapear las posiciones de los actores a partir de los vínculos establecidos entre ellos. La estructura de la red resulta del traslapo de personas en los contactos sociales. Este es el aspecto que se aborda a continuación.

\footnotetext{
${ }^{18} \mathrm{Al}$ momento de revisar este artículo, el Presidente Electo Sebastián Piñera procedió a nombrar sus ministros entre los cuales se encontraban varios empresarios. A juzgar por la reconocida ausencia de contactos de éstos con "el mundo político" las respuestas al cuestionario no se alejan de la realidad.
} 


\section{La red de poder de la élite política}

Las vinculaciones mencionadas por los entrevistados al identificar sus redes personales permiten establecer un mapa a través de sus vinculaciones indirectas, vale decir a través de intermediarios ${ }^{19}$. Dado que el entrevistado identificó explícitamente al miembro de la red, cuando existe coincidencia en un nombre el vínculo corresponde a la misma persona y no una posición o rol general. En la medida que un contacto está presente en más de una red, ello establece una pauta de relación susceptible de analizar. A partir de esta propiedad, se puede representar la red como un conjunto, pues no se encontraron redes personales aisladas.

Muchas de las relaciones presentadas en el mapa son indirectas, pues resultan de dos entrevistados distintos mencionando una misma persona. Ahora bien, el vínculo mencionado por un entrevistado se establece a partir de relaciones de confianza, que generalmente son transitivas; es decir, en un trío la relación de confianza de uno con dos de ellos involucra que el vínculo restante sea también de confianza (Granovetter 1973, Heider 1958). Por lo anterior es posible suponer que las relaciones identificadas, si bien indirectas, tienen alta probabilidad de existir en realidad o que al menos son reales en sus consecuencias.

La aproximación a la red completa a partir de redes personales está sujeta a riesgos derivados de la estrategia muestral de "snowball" pues ella tiende a producir grupos dispersos. En primer lugar, la red podría haber resultado desconectada porque su punto de partida son informantes individuales. Si aparecen sub-redes o nodos desconectados es legítimo preguntarse si ello habría sido así aplicando otra estrategia muestral. El segundo problema es que el mapa tienda a producir una estructura de centro-periferia, en la cual el centro lo ocupan los entrevistados. Ello puede ocurrir con más probabilidad cuando no existen vínculos indirectos entre los diversos entrevistados; aunque la presencia de conexiones por sí solo constituye una información relevante cuando se sigue esta estrategia (Moore 1979).

La estrategia muestral moderó los efectos del diseño sobre la estructura estableciendo una segunda ola de entrevistas aplicada a los contactos mismos, lo cual tiende a cerrar la red como sistema de relaciones. De esta forma se puede apreciar que la red completa está conformada por un solo componente; en otras palabras, no aparecen nodos o subredes desconectadas. En cuanto a la estructura centro periferia, ella está presente aunque no son necesariamente los entrevistados quienes ocupan las posiciones centrales. De todas formas, se trata de datos generados en una sola entrevista, lo cual constituye su principal debilidad; al respecto sólo cabe esperar que otros estudios contrasten los hallazgos de éste.

\footnotetext{
${ }^{19}$ Aunque estos datos corresponden a redes personales, hay una diferencia clave con respecto a los datos del PNUD (2005), pues los nombres de los contactos están identificados.
} 
Como resultado de la encuesta de redes hay un conjunto de 2262 vínculos entre 1177 contactos identificados a partir de una encuesta de redes; vale decir, dejando de lado menciones generales que sólo agregan ruido a la representación; respuestas del tipo "todos", "la mayoría”, "familiares”, etc. De éstos hay 889 vínculos únicos de cada entrevistado, vale decir personas que no están conectadas con otros integrantes de la red. Por estas razones, los totales varían con respecto a las cifras entregadas en la primera parte, que consideraron todas las menciones de los entrevistados.

Un gráfico que presentara todos los nodos y vínculos resultaría no solo de alta complejidad sino poco informativo, por la cantidad de contactos y lazos establecidos, de forma que se optó por una representación más compacta compuesta por 809 vínculos entre 121 nodos. Los nodos seleccionados corresponden a quienes señalaron que poseían una relación activa y fuerte con su contacto. El gráfico o sociograma representa, entonces, la cercanía social entre miembros de la élite, intermediada por personas entrevistadas o no pero que mantienen relaciones activas con más de un entrevistado. La relación reviste importancia sustantiva, por cuanto el artículo ha buscado establecer cómo las vinculaciones políticas se mezclan con vinculaciones sociales informales. La relevancia empírica viene dada porque se refieren a lazos establecidos con anterioridad al cargo parlamentario, por lo que reflejan vinculaciones sociales que no han sido originadas en el ejercicio del cargo.

El sociograma de la red se construyó utilizando Netdraw, programa que genera una representación basada en un escalamiento multidimensional (MDS) “energizado" con algoritmos destinados a equilibrar las distancias entre nodos (DeJordy et al 2007, Borgatti 2002). De esta forma, el gráfico muestra más cerca los puntos que están a menos distancia entre ellos medida en número de intermediarios entre uno y otro nodo- por lo que puede interpretarse como un mapa de proximidad o afinidad social. En el sociograma, el tamaño de los nodos indica el prestigio de las personas de acuerdo con el número de menciones que recibieron de otros entrevistados; coloquialmente puede decirse que los nodos de mayor tamaño representan a los "pesos pesados". Los colores de los nodos -blanco, negro y tonos de gris- representan los resultados de un análisis de conglomerado realizado tomando como medida la distancia más corta entre dos nodos cualquiera, cuya interpretación se presenta posteriormente. Finalmente, las formas de los nodos representan el partido político al cual pertenece cada nodo. Los cuadrados representan a los independientes, el rombo, PDC; el triángulo hacia arriba, UDI; el triángulo hacia abajo, RN; los triángulos superpuestos, PPD; el círculo encerrado en un cuadrado, PS; círculo, dignatarios católicos.

En el sociograma, un primer principio de organización espacial corresponde a la distancia ideológica entre dos bloques. En el sector superior encontramos principalmente los triángulos que representan a la UDI y RN, pero principalmente la primera, mientras que en sector inferior se encuentran los símbolos que representan a los partidos de la Concertación. Ambos 
sectores aparecen separados por un espacio de menor densidad de vínculos, lo cual refleja la brecha ideológica al interior de la élite política. Cabe hacer notar, sin embargo, que la densidad de vínculos es mucho más pequeña en el espacio superior que en el inferior. Puede afirmarse, entonces que las vinculaciones sociales en lo grueso siguen las adscripciones ideológicas. Ello no debiera extrañar dado que buena parte de los miembros de la élite política provienen del período de dictatorial, durante el cual el clivaje político segregó profundamente las relaciones sociales.

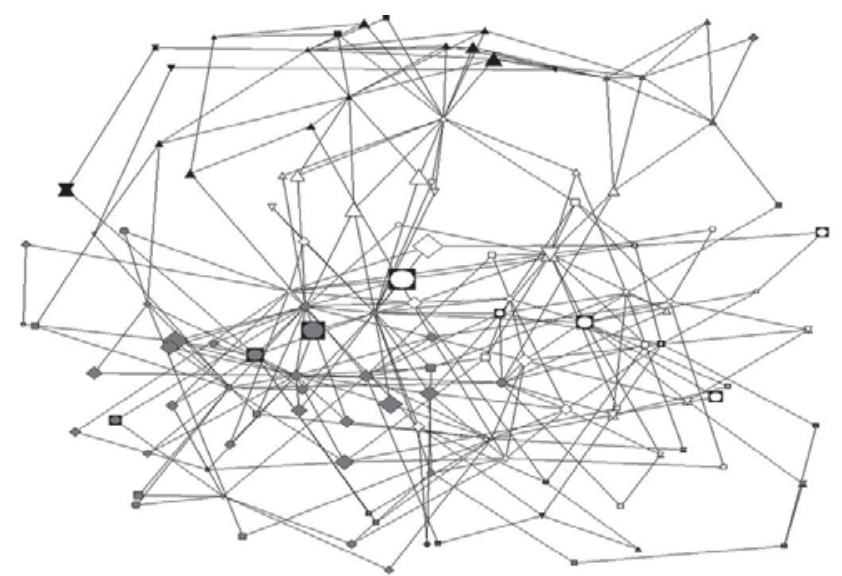

Sociograma 1: Relaciones sociales previas al ejercicio del cargo y actualmente activas entre miembros de la élite politica

SIMBOLOGIA

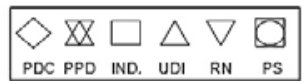

En este sentido resulta interesante advertir que los nodos independientes que aparecen en el sociograma -rectores de universidades, dignatarios eclesiásticos, o intelectuales- están socialmente ubicados en el campo de los políticos concertacionistas.

El análisis de conglomerados permite visualizar diferencias más precisas al interior de los grandes bloques. En el bloque superior, predominantemente UDI, se aprecia una diferencia entre negros más hacia la periferia y blancos más hacia el centro. Al revisar los nombres de sus integrantes que no se revelan por compromiso de confidencialidad- puede apreciarse que los negros corresponden a la "vieja guardia" de la UDI, vinculados directamente con Jaime Guzmán, y cuya vinculación se remonta a los cargos que ocuparon durante la dictadura; especialmente en alcaldías y secretarías sectoriales. Un segundo grupo que se representa en color blanco aparece más próximo al centro del sociograma, revelando vínculos hacia políticos de la Concertación, aunque no necesariamente aquellos que han alcanzado más prestigio. Es interesante advertir que estos políticos forman 
parte de un conglomerado que comprende miembros del espacio concertacionista, de forma que, aparentemente, tienden a difuminarse las distancias ideológicas.

En el campo en el cual predominan los partidos de la Concertación encontramos dos sectores que también se reflejan en el análisis de conglomerados. Hacia la izquierda del gráfico predominan los militantes democratacristianos (rombos) acompañados por algunos socialistas -los que, no obstante, están distribuidos por todo el arco concertacionista. Este sector representado en gris corresponde al núcleo más tradicional de la Concertación, aquel establecido durante los años 80; su composición muestra actores de edad similar, quienes tienen experiencias históricas comunes -la modernización de los años 1960, el gobierno dictatorial y el plebiscito contra la dictadura. Este conglomerado viene a ser lo que más de un entrevistado identifica como «la élite del no», articulada por actores políticos y sociales clave en el plebiscito de 1988. No está demás recordar que los democratacristianos entrevistados eran en su mayoría ex-parlamentarios por lo cual sus redes remiten a este tipo de contactos y a socialistas activos que ocupan posiciones relevantes en la actualidad.

Un socialista y un demócrata-cristiano de alto prestigio, es decir, mencionados como relación activa por muchos entrevistados, ocupan el centro del sociograma; la diferencia entre ambos reside en que, socialistas relativamente prestigiosos (círculo encerrado en un cuadrado) se distribuyen en arco por todo el campo concertacionista, de forma que se puede afirmar que constituyen su columna vertebral. La separación que establece el análisis de conglomerados puede asociarse con lo que algunos comentaristas han denominado "las dos almas de la Concertación”. Si la primera corresponde a la generación que afianzó sus lazos sociales y políticos en la lucha contra la dictadura ¿̇a qué corresponde el segundo bloque?

En este bloque representado en blanco se reduce la brecha ideológica con los sectores que respaldaron la dictadura. Aparecen también mencionados personas que no son militantes políticos activos, tales como intelectuales, artistas y rectores de universidades. En este campo se aprecian puentes entre generaciones políticas más jóvenes y de mayor edad, un espacio que remite en primer lugar a las universidades. Otro elemento de relevancia, que vincula con generaciones más jóvenes son los líderes regionales, tanto en la Concertación como en la Alianza. Finalmente, hacia la periferia de este sector, aparecen algunos políticos más jóvenes, vinculados críticamente con la Concertación.

La diversidad, social, política e ideológica de este sector lo establece como un campo propicio para iniciativas de renovación política. Siendo un sector unido por muchos vínculos sociales con la Concertación, su expansión se encuentra en directa competencia con el espacio ocupado por la antigua generación del No, que domina aún el centro de gravedad de la escena política. El potencial de este sector sólo puede expresarse plenamente en la medida que logre diferenciarse de quienes dominan hoy el campo 
concertacionista, probablemente desplazando el centro de gravedad hacia un campo de mayor labilidad ideológica.

Los resultados del análisis muestran que en el sustrato social de la vida política, tal como lo expresan las relaciones sociales informales de su élite perviven cada vez más debilitados los rastros del quiebre político realizado por la dictadura. Miembros de una misma generación respaldaron a la dictadura y lucharon contra ella. La imagen de sus relaciones sociales muestra como los clivajes políticos alcanzaron a las relaciones sociales, estableciendo segmentaciones tan radicales como exilio o veto en los trabajos, sin descontar la persecución política. Aun cuando quienes hoy dominan la escena política provienen de círculos sociales semejantes, no mantuvieron relaciones sociales activas entre si. Por contraste, quienes se han incorporado a la política durante el período posterior a la dictadura han tenido la oportunidad de convivir con sus adversarios ideológicos en dos campos principales: las universidades y las regiones.

Si los protagonistas de la política post-dictatorial son más jóvenes, varias de sus contrapartes pueden pertenecer a la generación anterior, sin ocupar posiciones de primer plano. En el caso de las universidades, líderes políticos de distinta orientación ideológica no sólo han compartido las aulas, sino que incluso han sido ayudantes de los mismos profesores. De forma similar en las regiones se recompone una relación intergeneracional alrededor de alcaldes o parlamentarios de alto peso político local. Estos líderes parecen tener la capacidad para recomponer la relación entre generaciones, no necesariamente asociadas con subordinaciones derivadas del control de recursos políticos, como ocurre en la generación de la dictadura.

\section{Comentarios finales}

Al analizar los aspectos relacionales de la élite política se pueden establecer algunas características que no son evidentes a partir del estudio de sus rasgos individuales. En primer lugar, debe destacarse que su origen social diverso va en vías de mayor homogeneidad, lo cual aparece convergente con los resultados de estudios anteriores. En particular, se aprecia menor peso de la educación pública en favor de la educación privada, en la formación de las generaciones más jóvenes de la élite política, lo cual se encuentra asociado también a mayor status socio-económico de las familias de origen. Hasta el momento, no obstante, los colegios no establecen un ámbito de relaciones sociales que se mantengan activas en la vida política.

El mapa social de la élite política, que considera tanto sus relaciones internas como las vinculaciones con personas que no son miembros de la élite, constituye un elemento descriptivo clave para comprender los procesos de reclutamiento y diferenciación interna en la élite política. La interpretación de este mapa ha permitido establecer la oportunidad para la integración horizontal, expresado como participación conjunta en espacios que 
constituyen experiencias sociales significativas (colegios, universidad, exilio, pertenencia comunitaria, etc.). En forma complementaria, el mapa permite apreciar las vinculaciones externas a la red, de forma que pone a la élite política en su contexto social.

El análisis muestra, en definitiva, que la preeminencia política puede diferenciarse del origen social de sus portadores, visto a partir de sus relaciones sociales más fuertes y activas. No hay indicación, por el momento de que el actor político de élite "derive" su poder de otro círculo-familiar, económico, religioso o social. Por cierto que mantiene relaciones con todos estos círculos, incluso el manejar un conjunto exclusivo de vinculaciones es parte de las razones por las cuales se encuentra en posiciones de élite, pero ello está lejos de constituir subordinación, porque su posición dentro de la red le otorga gran autonomía.

La profunda fractura social que infirió la dictadura a la sociedad chilena queda de manifiesto al verificar que las relaciones sociales entre adversarios políticos hasta el día de hoy establece a una distancia insalvable para los miembros de esa generación. La respuesta a nuestra pregunta inicial acerca de la estabilidad del bloque concertacionista en el gobierno debe entenderse fundamentalmente como expresión de un clivaje, que más allá de lo ideológico alcanzó la estructura social misma. La ausencia de puentes entre ambos sectores, unido a la capacidad para mantener los recursos de fuerza al margen del escenario político garantizaron la permanencia del sector políticamente más consistente. Es posible hipotetizar entonces que la transformación del bloque en el gobierno e incluso la alternancia tienen como condición el establecimiento de un espacio social más fluido y un debilitamiento en la consistencia interna de la Concertación.

El sociograma de afinidades sociales permite apreciar, en este sentido, la apertura de un cierto espacio político post-dictatorial más diverso en lo social, pues incorpora intelectuales junto con políticos; en lo generacional, pues es menos homogéneo en edades que el resto del campo examinado; geográficamente, pues se expresa en la vinculación con líderes políticos locales; e ideológicamente, pues las fronteras entre bloques aparecen más difusas. La universidad, pública o privada es el espacio clave en el cultivo de estas relaciones, pues aparece no solamente como el lugar donde los jóvenes interesados por la política inician su militancia más activa, sino como un punto de encuentro con futuros aliados y adversarios, así como con líderes intelectuales que desafían sus puntos de vista. 


\section{Bibliografía}

Adler-Lomnitz, L. \& Pérez-Lizaur, M. (1987), A Mexican elite family, 18201980: kinship, class, and culture, Princeton, N.J.: Princeton University Press.

Alba, R. D. \& Moore, G. (1983), Applied Network Analysis, Sage, chapter Elite social circles, pp. 167-88.

Alcántara-Sáez, M. \& Llamazares-Valduvieco, I. (1997), “El análisis de los diputados latinoamericanos en el contexto de los estudios sobre la clase política. Características, objetivos y estrategias de investigación”, América Latina Hoy. Revista de Ciencias Sociales 16, 15-28.

Alcántara-Valverde, N. \& Casasola-Vargas, S. P. (2002), Análisis de redes. Aplicaciones en ciencias sociales, Mexico D.F.: IIMAS-UNA, chapter La estrategia matrimonial de la red de poder de Guatemala colonial, pp. 158-178.

Barro, R., Lee J.W. (2000), International Data on Educational Attainment: Updates and Implications. CID Working Paper 42 (April).

Berkowitz, S. (1982), An Introduction to Structural Analysis. The Network Approach to Social Research, Toronto: Butterworths.

Borgatti, S.P. (2002), NetDraw: Graph Visualization Software. Harvard: Analytic Technologies.

Bourdieu, P. \& Wacquant, L. (1992), An Invitation to Reflexive Sociology, University of Chicago Press; Cambridge: Polity Press, Chicago, IL.

Bottomore, T. (1964), Elites and Society, London: Peguin Books.

Burt, R. S. (1992), Structural Holes, Harvard University Press, Cambridge, Mass.

Burt, R. (2005), “Dimensiones reticulares del capital social” en Espinoza, V., Porras, J.I. (editores). Introducción a la teoría y práctica del análisis de redes sociales (ARS), Instituto de Estudios Avanzados de la Universidad de Santiago - Universidad Bolivariana.

Cavarozzi, M. (1992), Elites and Democratic consolidation in Latin America and Southern Europe, Cambridge University Press, chapter Patterns of elite negotiation and confrontation in Argentina and Chile, pp. 208-236.

Coenen-Huther, J. (2004), Sociologie des élites. Armand Colin, Paris.

Cordero, R. (2007), “La Composición Social de la Nueva Cámara de Diputados: Cambios y continuidades en perspectiva histórica (1961-2010)”, 
en Huneeus, C. Berríos, F., Gamboa, R. Las elecciones chilenas de 2005: partidos, coaliciones y votantes en transición. Santiago, Catalonia.

DeJordy, R.; Borgatti, S. P.; Roussin, C. \& Halgin, D. S. (2007), "Visualizing Proximity Data”, Field Methods 19(3), 239-263.

Dahl, R. A. (1958), “A Critique of the Ruling Elite Model”, The American Political Science Review 52(2), 463-469.

Domhoff, G. W. (1967), Who Rules America? (1st ed.), Englewood Cliffs, NJ: Prentice-Hall.

Edwards, A. (1982), La Fronda aristocrática en Chile. Santiago, Universitaria.

Espinoza, V. (1999), Networks in the Global Village, Westview Press: Boulder, CO, chapter Social Networks among the Urban Poor. Inequality and Integration in a Latin-american City, pp. 147-184.

Espinoza, V. \& Madrid, S. (2010), Trayectoria y eficacia política de los militantes en juventudes políticas. Estudio de la élite política emergente, Santiago: PNUD.

FLACSO-Chile (2007). Funcionamiento interno de los partidos políticos en Chile. Un diagnóstico. Santiago, FLACSO.

Gazmuri, C. (2001), Notas sobre las élites chilenas (1930-1999). Discurso de incorporación como académico de número a la Academia Chilena de Historia y publicado por la misma.

Giddens, A. (1974), Elites and power in British society, London, New York: Cambridge University Press, chapter Elites in the British Class Structure, pp. 22-44.

Giddens, A. (1990), The Consequences of Modernity. Cambridge, Polity.

Góngora, M. (1986), Ensayo histórico sobre la noción de Estado en Chile, siglos $X I X$ y $X X$, Santiago, Ed. Universitaria.

Granovetter, M. (1973), “The Strength of Weak Ties”, American Journal of Sociology, Vol. 78, Issue 6, May 1973, pp. 1360-1380.

Granovetter, M. (1985), “Economic Action and Social Structure: The Problem of Embeddedness”, The American Journal of Sociology 91, 481510.

Hardy, C. (2005), Eliterazgo: liderazgos femeninos en Chile. Santiago, Catalonia. 
Heider, F. (1958), The Psychology of Interpersonal Relations, New York: Wiley.

Highley, J.; Hoffmann-Lange, U.; Kadushin, C. \& Moore, G. (1991), “Elite integration in stable democracies: a reconsideration", European Sociological Review 7(1), 35-53.

Huneeus, C. (2002, El régimen de Pinochet. Santiago, Alianza Editorial.

Hyman, H.H. (1959), Political Socialization. A Study in the Psychology of Political Behavior. Free Press.

Joignant, A., Navia, P. (2003) “De la política de individuos a los hombres del partido. Socialización, competencia política y penetración electoral de la UDI (1989-2001)”, Estudios Públicos 89 (verano 2003).

Kadushin, C. (1968), "Power, Influence and Social Circles: A New Methodology for Studying Opinion-Makers”, American Sociological Review 33, 685-699.

Knoke, D. (1990), Political networks: the structural perspective. Cambridge [England]; New York: Cambridge University Press.

Lin, N. (2001), Social Capital: A Theory of Social Structure and Action. Cambridge, Cambridge University Press, New York.

Michels, R. ([1911] 1983), Los partidos políticos, Ed. Amorrortu, Buenos Aires.

Miliband, R. (1974), El Estado en la Sociedad Capitalista, Mexico, Siglo XXI.

Mills, C. W. ([1956] 1987), La élite del poder. 4a Ed., Fondo Cultura Económica, México.

Moore, G. (1979), “The structure of a national elite network', American Sociological Review 44 (October), 673-91.

Morris J.O. (1967), Las élites, los intelectuales y el consenso. Editorial del Pacífico S.A.

Mosca, G. (1984 [1896]), La clase política, Fondo de Cultura Económica. Mexico DF.

Nolte, D. (2003), “l Congreso chileno y su aporte a la consolidación democrática en una perspectiva comparada’, Revista de Ciencia Política, volumen XXIII / $N^{\circ}$ 2, 43-67.

O’Donnell, G.; Schmitter, P. C. \& Whitehead, L. (1986), Transitions from 
Authoritarian Rule: Comparative Perspectives, Baltimore, Maryland, U.S.A. Johns Hopkins Univ Press.

Pareto, V. (1935 [1916]), The Mind and Society: A Treatise on General Sociology. Ed. A. Livingston. Trans. A., Bongiorno \& A. Livingston. Dover, New York.

Pinto, A. (1971), “Desarrollo económico y relaciones sociales” en Pinto, A. et al. Chile hoy. México DF: Siglo XXI.

PNUD (2005), El poder: para quién y para qué. PNUD, Santiago.

Portes, A. (1998), "Social Capital: Its Origins and Applications in Modern Sociology”, Annual Review of Sociology 24, 1-24.

Putnam, R. D. (1976), The Comparative Study of Political Elites. PrenticeHall, Englewood Cliffs, N.J.

Rabkin, R. (1996), “Redemocratization, Electoral Engineering and Party Strategies in Chile (1989-1995)”. Comparative Political Studies 29: 335356.

Ruiz Schneider, C. (1993), Seis Ensayos sobre Teoría de la Democracia, Santiago: Universidad Nacional Andrés Bello.

Santa Cruz, L. (2004), “La nueva élite”. El Sábado (El Mercurio), 10 de abril del 2004.

Santa-Cruz, L. \& Guzmán, E. (2008), “Nosotros somos la élite”, Revista Universitaria 99, 32-39.

Sawicki, F. (1997), Les réseaux du Parti socialiste. Sociologie d’un milieu partisan. Paris, Belin.

Scott, J. (2008), "Modes of power and the re-conceptualization of elites"” Sociological Review 56(s1), 25-43.

Stabili, M. R. (2003), El sentimiento aristocrático. Elites chilenas frente al espejo (1860-1960), Santiago: Editorial Andrés Bello y Centro de Investigaciones Diego Barros Arana.

Thumala Olave, M. A. (2007), Riqueza y piedad : el catolicismo de la elite económica chilena, Buenos Aires: Debate.

Wasserman, S. Faust, K. (1994), Social Network Analysis: Methods and Applications. CUP, 1994.

Wellman, B. (2000), “El análisis estructural: del método y la metáfora a la teoría y la sustancia”, Política y Sociedad(33). 
Wellman, B. \& Wortley, S. (1990), “Different strokes from different folks”, American Journal of Sociology 96, no. 3, 558-88.

White, D. (1994), "Enfoque de redes para el estudio de comunidades urbanas”, Revista de Estudios Demograficos y Urbanos Vol. 9, N², mayoagosto, 303-326.

Zeitlin, M. \& Ratcliff, R. E. (1988), Landlords and capitalists, The dominant class of Chile, Princeton University Press, Princeton. 